\title{
Historical retrospective of the $S R C$ oncogene and new perspectives (Review)
}

\author{
ARISTOFANIA SIMATOU ${ }^{1}$, GEORGE SIMATOS ${ }^{1}$, MARIA GOULIELMAKI ${ }^{2}$, \\ DEMETRIOS A. SPANDIDOS ${ }^{3}$, STELLA BALIOU ${ }^{2}$ and VASSILIOS ZOUMPOURLIS ${ }^{2}$ \\ ${ }^{1}$ First Breast Unit, Saint Savas Cancer Hospital, 11522 Athens; ${ }^{2}$ Biomedical Applications Unit, \\ Institute of Chemical Biology, National Hellenic Research Foundation (NHRF), 11635 Athens; \\ ${ }^{3}$ Laboratory of Clinical Virology, Medical School, University of Crete, 71003 Heraklion, Greece
}

Received June 11, 2020; Accepted July 14, 2020

DOI: $10.3892 / \mathrm{mco} .2020 .2091$

\begin{abstract}
Since its first discovery as part of the Rous sarcoma virus (RSV) genome, the c-SRC (SRC) proto-oncogene has been proved a key regulator of cancer development and progression, and thus it has been highlighted as an attractive target for anti-cancer therapeutic strategies. Though the exact mechanisms of its action are still not fully understood, SRC protein mediates crucial normal cell functions, such as cell development, proliferation and survival, and its dysregulation is considered as an oncogenic signature and a driving force for cancer initiation. In the present review, we present a flashback to the history of the $S r c$ research, while focusing on the most important milestones in the field. Moreover, we investigate the proposed regulatory mechanisms and molecules that mediate its action in order to designate putative therapeutic targets and useful prognostic and/or diagnostic tools. Furthermore, we present and discuss existing therapeutic approaches that are explored in clinical settings.
\end{abstract}

\section{Contents}

1. Introduction

2. Discovery of Rous sarcoma virus

3. Cellular origin of retroviral oncogenes

4. MicroRNAs as the fine tuners of SRC oncogenic signaling

5. miRNA-mediated SRC oncogenic signaling in selected cancer types

6. Exosomes as the fine tuners of oncogenic signaling

7. SRC inhibitors as anticancer agents in clinical trials

8. Conclusion

Correspondence to: Dr Vassilios Zoumpourlis, Biomedical Applications Unit, Institute of Chemical Biology, National Hellenic Research Foundation (NHRF), 11635 Athens, Greece

E-mail:vzub@eie.gr

Key words: Src oncogene, Rous sarcoma virus, carcinogenesis, cancer therapy, miRNAs

\section{Introduction}

The proto-oncogene $c$-SRC (SRC) is a non-receptor tyrosine kinase, its expression and activity is enhanced in various human cancers and correlates with malignancy progression and development of distant metastasis (1-3). Since there is increasing evidence of its crucial role in tumor progression $(4,5) c-S R C$ has emerged as a promising target for anticancer therapy. Consequently, SRC inhibitors have been evaluated in the development of clinical therapies $(6,7)$. However, the exact mechanisms of action of $c-S R C$ and the critical respective pathway involved in malignancy are not fully elucidated.

c-SRC is involved in the maintenance of normal cell homeostasis regulating a wide range of cellular events, including cell growth, differentiation, proliferation, survival, adhesion, migration and motility $(8,9)$. In normal cells, the expression levels and activity of c-SRC are strictly regulated by several mechanisms. The kinase activity of c-SRC is controlled by C-terminal SRC kinase (CSK), which phosphorylates a conserved tyrosine residue in the c-SRC carboxy-terminal domain (Tyr530). This is reversed by phosphatases such as protein tyrosine phosphatase 1B (PTP1B), resulting in c-SRC activation. Additionally, activation of growth-factor receptors leads to their association with the c-SRC homology 2 (SH2) domain, which disrupts inhibitory intramolecular interactions to promote c-SRC activation. Other proteins, such as CRK-associated substrate (CAS) and FAK, bind to the c-SRC SH2 and SH3 domains to stimulate c-SRC activation by a similar mechanism. Moreover, c-SRC is also negatively regulated via the ubiquitin-proteasome pathway, which is mediated by E3 ubiquitin-ligase $\mathrm{Cbl}$ and Cullin-5 (10-12). Hence, c-SRC is regulated at both transcriptional and post-translational levels by a variety of mechanisms (10-12). The disruption of any of the c-SRC regulatory mechanisms may trigger cancer phenotypes through uncontrolled proliferation, enhanced survival, and invasiveness, in cooperation with other oncogenic signals (2). Once activated, as by growth factors or integrins, c-SRC triggers downstream signaling pathways, including the RAS/MAPK, phosphatidylinositol 3-kinase (PI3K)/AKT, and STAT pathways, leading to malignant phenotypic changes (13). 


\section{Discovery of Rous sarcoma virus}

In 1909, at the Rockefeller Institute, Peyton Rous started his studies on a sarcoma that had been developed in the breast muscle of a hen. In his original experiments, Rous managed to transmit the tumor to other birds of the same species, by implanting fragments of the initial tumor. In his subsequent experiments, he developed a short protocol for the induction of tumors in chickens. He used a chicken with sarcoma of breast muscle, removed the mass and broke it up into small chunks of tissue. Subsequently he ground up sarcoma with sand and filtrated it through a fine pore filter. Finally, he injected the filtrate into a young chicken, and observed the growth of sarcomas. He then hypothesized that the tumor-inducing agent should be an oncogenic virus, later becoming known as Rous sarcoma virus (RSV), since this agent was possible to pass through a filter too fine to contain bacteria or chicken cells and was capable of causing cancer with a predictable pattern $(14,15)$. This finding was of great importance as it was the first proof of viral carcinogenesis and thus triggered the discovery of many other types of tumor-inducing viruses in non-human primates such as mice, cats, rabbits (16-19) and later, of the first oncogenic human virus, Epstein Barr in 1964 (20). Additionally, the discovery of this pioneer oncogenic retrovirus (RSV) was the hallmark of the onset of the development of research on the molecular mechanisms of carcinogenesis (21).

For almost half a century the research interest was focused on chemical carcinogenesis (22-27). The revival of research regarding oncogenic retroviruses came in 1958 in the Laboratory of Renato Dulbecco. Temin and Rubin developed a quantitative in vitro bioassay for the transformation of normal chicken embryonic fibroblasts with RSV. More specifically, in their experiment, they showed that when the virus was introduced to Petri dishes where embryonic fibroblasts where cultured, the RSV(+) cells obtained an evolutionary advantage and were transformed, acquiring cancer morphology under the microscope, i.e., they were less adherent and often rounded up, with increased size and/or number of nucleoli (28). In 1966, the Nobel prize was finally awarded to Peyton Rous for his discovery. The next question that arose was whether the transformation of cellular phenotypes was due to the constant influence of the RSV genome. In 1970, an experiment in Berkeley confirmed the above hypothesis. In this experiment, when fibroblasts where cultured with a heat-sensitive mutation of RSV at permissible temperatures $\left(37^{\circ} \mathrm{C}\right)$ the cells were transformed. When the cultures containing these cells were transferred to an impermissible temperature $\left(41^{\circ} \mathrm{C}\right)$, the fibroblasts regained their normal morphology and they re-acquired a cancerous morphology when re-exposed to $37^{\circ} \mathrm{C}$. It was evident that the transforming phenotype was maintained from the ongoing effects of this protein (29-31). The Src oncogene of RSV became the prototype for dozens of other transforming genes in oncogenic viruses. Its product was identified by Brugge and Erikson in 1977, as a protein with tyrosine-kinase activity.

\section{Cellular origin of retroviral oncogenes}

In 1961, the RSV was proved to contain an RNA genome (32), whose continuous presence was necessary for maintaining cell transformation. However, the mechanism by which the viral RNA genome was incorporated into the infected cells remained undefined. In 1970, the simultaneous research of Temin and Baltimore led to the discovery of reverse transcriptase, an enzyme that catalyzes the transcription of the retroviral RNA into DNA (33), and that is also present in RSV. Through reverse transcriptase, the monoclonal RNA of the virus is converted to a double-stranded DNA, and the viral genome is then incorporated into the nuclear DNA via another enzyme, called integrase (34). Initially, it was considered that a copy of the src transforming gene exists only within infected cells (35-38). In 1974, the laboratory of Michael Bishop and Harold Varmus, taking advantage of the reverse transcriptase, undertook the design of a special gene detector for $s r c$, in order to understand its properties and origin. To their surprise, they found that the $\operatorname{src}$ detector could also be hybridized with the genetic material of non-infected cells of chicken and other species (two copies per genome of diploid cells) $(35,37,38)$. They also observed that the more distant the evolutionary affinity with the chicken, the weaker the degree of hybridization. The data supported the idea that the $s r c$ sequences found in non-infected cells, are actually part of their normal genome (the cellular version of $s r c=c-s r c)$ (35-39). In 1975, the Nobel prize was awarded to Temin and Baltimore, for the discovery of reverse transcriptase $(33,34)$.

From 1976 to 1980 the research focused on the differences between the c-src and, the v-src, which is located within the RSV genome. The first one exhibited physiological cellular behavior as opposed to the second, which acts as a potent oncogene. The explanation was simple; the src gene of RSV was not initially present in the primordial RSV retrovirus. A pre-existing virus (ALV=src negative) was detected that caused leukosis in birds and which, through genetic modifications, incorporated sequences from the genome of infected cells (RSV $=s r c$ positive). Subsequent experiments showed that the structure of the RSV genome is closely related to this common infectious agent of birds, called ALV (35-40). Both of them include three genes: Gag, pol and env. The gag gene encodes for proteins that take part in the formation of the nucleoprotein nucleus; the pol gene encodes for integrase and reverse transcriptase; and the env gene determines the glycoprotein precursors. The only difference between the two genomes lies in the ability of the $s r c$ gene to cause cellular transformation $(39,40)$. Thus, for the first time, the concept of proto-oncogene was introduced, implying that a normal gene can be altered by mutation or by a pre-viral insertion, to become an oncogene, thereby contributing to cancer development. Since 1980, retroviruses have been used as probes, to detect the corresponding proto-oncogenes in humans, and researchers have shifted the focus on chemical carcinogenesis (41-43). This second theory confirmed the cellular origin of retroviral oncogenes and additionally contributed to the unravelling of possible mechanisms for proto-oncogene activation, such as amplification, pre-viral insertion, single nucleotide polymorphism and translocation (41-45). In 1989, the Nobel prize was awarded to Bishop and Varmus for the discovery of the cellular origin of retroviral oncogenes $(46,47)$. The most important historic milestones on $\mathrm{Src}$ research are presented in Fig. 1.

\section{MicroRNAs as the fine tuners of SRC oncogenic signaling}

As mentioned above, c-SRC is the first reported oncogene and its product is the first non-receptor tyrosine kinase to be identified (48). In many human neoplasms, including 


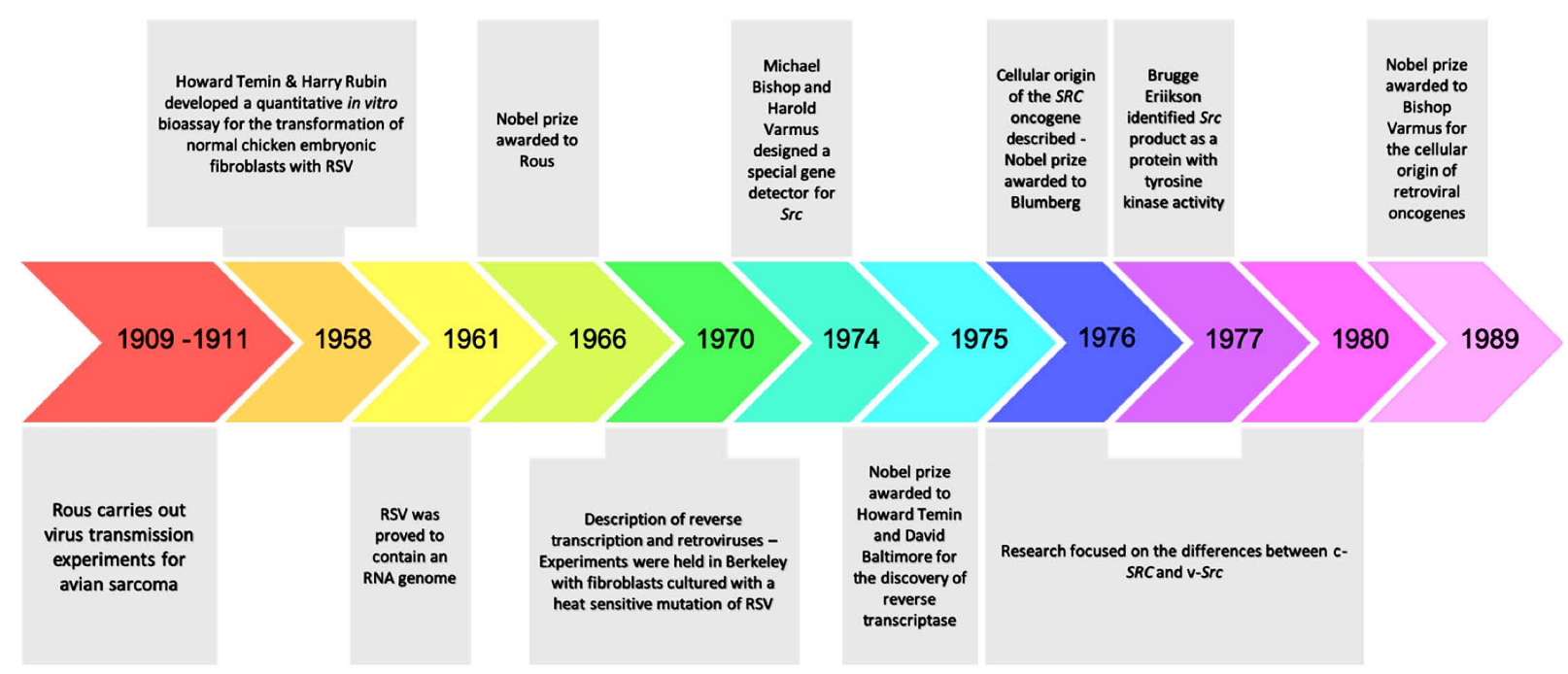

Figure 1. Historical retrospective of the major discoveries regarding the $\mathrm{Src}$ oncogene.

colorectal, breast, prostate, pancreatic, head and neck, and lung carcinomas, gliomas and melanoma, $S R C$ overexpression has already been detected. In fact, its dysregulation could be characterized as an oncogenic signature and as a key factor for tumor progression $(3,5,49)$. However, the molecular mechanisms underlying c-SRC-mediated tumor progression are not fully understood. Recent studies have highlighted several microRNAs (miRNAs) as key molecules in SRC-mediated tumor progression (50). miRNAs are a family of small, endogenous and evolutionarily conserved non-coding RNAs (containing about 22 nucleotides) involved in the regulation of essential cellular and functional processes, including proliferation, differentiation, survival and stress responses. The majority of miRNAs are transcribed from DNA sequences into primary miRNAs (pri-miRNAs) and processed into precursor miRNAs (pre-miRNA), and finally mature miRNAs. Their functionality is bimodal, since they locate complementary mRNAs and either regulate protein translation or induce degradation of the target mRNA (51). Hence, miRNAs act either as oncogenes or tumor suppressors and are important regulators of gene expression at the post-transcriptional level (52). In subsequent experiments, microarray profiling revealed that $\mathrm{c}-\mathrm{SRC}$ regulates a set of miRNAs, which act as tumor suppressors, when their expression is downregulated. Generally, miRNAs are commonly silenced in human cancers by mutation, methylation, loss of heterogeneity or by other post-transcriptional modifications (53). Studies on the function of these miRNAs uncovered miRNA-mediated c-SRC oncogenic signaling and crosstalk between $S r c$ and other oncogenic signaling pathways, such as the focal adhesion-mediated pathway and the mammalian target of rapamycin, mTOR (50).

Recently, the mechanisms underlying SRC-mediated activation of mTOR signaling, a major downstream effector of the PI3K pathway, were found to be regulated by miRNA expression in various cancer types $(54,55)$. More precisely, functional analysis showed that transcription of miR-99a, which is often downregulated in various human cancers, and is regulated by SRC-related oncogenic pathways, like the epidermal growth factor receptor (EGFR) pathway. It was demonstrated that mir-99a targets mTOR and fibroblast growth factor receptor
3 (FGFR3), both of which are strongly related with human cancers $(56,57)$. In conclusion, this study indicated that miR-99a is the missing link between SRC and mTOR, which have both been correlated with human cancer. Furthermore, miRNA-mediated mTOR regulation has also been shown in studies of miR-100 and miR-199-3p $(58,59)$. Further studies suggested that miRNAs also regulate focal adhesion and activation of downstream effectors in SRC-activated cancer cells. More specifically, integrin-linked kinase (ILK) is targeted by miR-542-3p, a downregulated miRNA in SRC-transformed cells (60-63). Apart from the fact that downregulation of miR-542-3p corresponds with upregulation of c-SRC and ILK, there is also a correlation between ILK upregulation and c-SRC activation in human colon cancer tissues. Furthermore, it was found that miR-542-3p-mediated ILK downregulation induces inactivation of c-SRC and FAK in human colon cancer cells (feedback loop).

Last but not least, miRNA mediates regulation of $S R C$ expression itself, and this could also be a logical explanation for the resistance that is observed when SRC-targeting drugs are used. In detail, miR-23b functions as a tumor suppressor and as a mediator of metastasis in different cell lines (64). miR-27b, which targets paxillin, a platform for adaptor proteins and a critical component of the focal adhesion complex, is under the control of the PI3K pathway (65-68). Taking into consideration that both of them are downregulated in human castration-resistant prostate cancers (69), c-SRC could be regulated by the miR-23b/27b 24-1 gene cluster via a dual mechanism: Regulation of c-SRC kinase activity via either miR-27b or miR-23b mediated regulation of paxillin. As a result, upregulation of $\mathrm{c}-S R C$ expression may amplify the positive-feedback loop mediated by the miR-23b/27b 24-2 gene cluster thus, inducing tumor progression mediated by c-SRC activity (50).

\section{5. miRNA-mediated SRC oncogenic signaling in selected cancer types}

As many miRNAs are down-regulated in human cancers through various genetic and epigenetic alterations, such as methylation and loss of heterogeneity, research was focused 
on the role of down-regulated miRNAs in c-SRC transformation (53). Subsequent experiments highlighted the key role of miR-137 in the development of SRC-mediated human colon cancer (70). To elucidate the role of miR-137 and its correlation with SRC signaling, the HCT116 cell line, anti-sense miRNAs and also dasatinib (a specific SRC kinase inhibitor) were used. It was finally concluded that miR-137 is down-regulated in the early stages of cancer progression (70). In another experiment, the role of miR-129-1-3p in human colon cancer was evaluated by assessing miR-129-1-3p expression in 10 pairs of primary colon tumors and adjacent non-cancerous tissues using qRT-PCR and western blot analysis to examine the activity of SFK (SRC pY418). It was clarified that miR-129-1-3p was markedly downregulated and SFK activity was greatly upregulated in colon cancer tissues (71). Additional studies demonstrated that certain miRNAs induce SRC oncogenic signaling by targeting SRCIN1, a specific SRC kinase signaling inhibitor. For example, miR-665 suppresses SRCIN1 expression, which normally acts as a negative regulator of MAPK/ERK signaling in ovarian cancer cells (72). In ovarian cancer, sustained activation of MAPK/ERK signaling is associated with strong cell proliferation and metastatic potential (73). The western blotting results showed that inhibition of miR-665 increased SRCIN1, at both the mRNA and protein level, and inactivated MAPK/ERK pathway in ovarian cancer (74). Similar findings were reported in the case of miR-150. It was observed that miR-150 promotes the proliferation and migration of lung cancer cells by targeting SRC kinase signaling inhibitor 1 (SRCIN1), therefore acting as an oncogene (75). Subsequent studies examined the role of miR-17-5p in the evolution of osteosarcoma and revealed a component of the miR-17-5p/SRCIN1/EMT signaling pathway. Furthermore, classic EMT markers such as N-cadherin, E-cadherin and Snail were quantified by western blot analysis. Finally, it was proven that SRCIN1 is a direct target of miR-17-5p and silencing of this miRNA could change the expression of EMT markers and arrest cell growth (76). SRCIN1 was found to be downregulated in breast cancer in previous studies (77). Moreover, miR-374a was shown to induce cell proliferation, invasion and migration of gastric cancer cell via binding to SRCIN1 (78). It was also found to be involved in pancreatic cancer through the axis miR-374a/SRCIN1/EMT (79). Finally, a recent study focused on the identification of miR-373 levels in metastatic neuroblastoma samples and its interaction with SRCIN1 (80).

In conclusion, it becomes evident that miRNA dysfunction is involved in various human cancers and miRNAs can function as both oncogenes and tumor suppressors $(81,82)$. Due to their implication in the regulation of sustained cell growth signaling, miRNAs are considered as potential biomarkers and therapeutic targets for cancer treatment (83).

\section{Exosomes as the fine tuners of oncogenic signaling}

As mentioned above, $S R C$ functions as a molecular signaling switch and plays a central role in the regulation of cell proliferation, differentiation, adhesion, and migration in normal cells (8), and is commonly upregulated in various human cancer cells. The activation of $S R C$ is strictly regulated by several molecular mechanisms. For example, the kinase activity of SRC is negatively regulated by the phosphorylation of a regulatory tyrosine at its c-terminal tail, catalyzed by CSK $(84,85)$. On the other hand, SRC is positively regulated through several extracellular signals, such as growth factors and extracellular matrices, which lead to the interaction with certain adaptor proteins, including FAK and Cas $(49,86)$, and consequently to the activation of downstream signaling pathways. Furthermore, cellular localization of SRC, determines its activity. Inactive SRC is located to the perinuclear region, and once activated, it is translocated to the plasma membrane, under the control of members of the Rho family (87).

Recent studies have shown that activated SRC is downregulated through degradation by either lysosomes or proteasomes, with the functional difference between them remaining unclear (10,88-90). More precisely, the E3 ubiquitin ligase Cbl mediates the ubiquitination of SRC and induces its degradation via the ubiquitin-proteasome pathway $(89,90)$. In a recent study, ubiquitination of activated SRC at Lys 429 was demonstrated to promote its secretion via small extracellular vesicles (sEVs) (91). In this experiment, MDCK cells expressing a modified $S R C$ that can be activated by hydroxytamoxifen were used in order to mimic SRC upregulated cancer cells. When proteasome inhibition (MG132) was performed, no accumulation of ubiquitinated SRC was noted, suggesting that ubiquitination of SRC preferentially promotes its secretion via SEVs to decrease the levels of activated SRC in these cells. It was also identified that Lys 429 is a critical ubiquitination site required for sEV-mediated secretion. In an attempt to determine how the mutation at Lys429 on SRC (R429) affects the cell, it was observed that it caused resistance to ubiquitination and decreased its secretion via sEVs. Additionally, since the cbl ablation caused a less potent suppression of the SEV secretion, it was hypothesized that other E3 ligases might also be required. In addition, activation of R429 mutant enhanced SRC-induced invasive phenotypes, supporting the hypothesis of a stronger activation of FAK at the early stages $(86,91)$. These findings have shed light on this missing link between SRC ubiquitination and SEV secretion, and suggest a tumor suppressive role for the secretion of SRC via sEVs. The fact that SRC is detected in exosomes from various cancer cells, such as colorectal (92), prostate (93), and breast (94) cancer cells, indicates that secretion of SRC via exosomes may be a common mechanism used to regulate SRC in a wide array of cell types and seems to constitute a novel promising therapeutic target (95).

\section{SRC inhibitors as anticancer agents in clinical trials}

The role of $S R C$ in oncogenesis has prompted the detection of other members of the SRC family of protein kinases and the search for anticancer therapies. To this end, most of the FDA-approved inhibitors of related protein kinases are directed toward neoplastic diseases. However, since SRC is not a primary driver of tumorigenesis, but rather a participant in pathways of cell division, invasion, migration and survival, administration of existing inhibitors of SRC as a monotherapy has not been proved efficient in cancer treatment (96). Moreover, there are currently no available prognostic biomarkers related to SRC activity that could be used for patient selection in clinical trials.

Currently, four oral SRC/multi-kinase inhibitors have been approved by the FDA for the treatment of various malignancies. Bosutinib, a BCR-Abl, SRC, Lyn, Hck, Kit, and PDGFR 


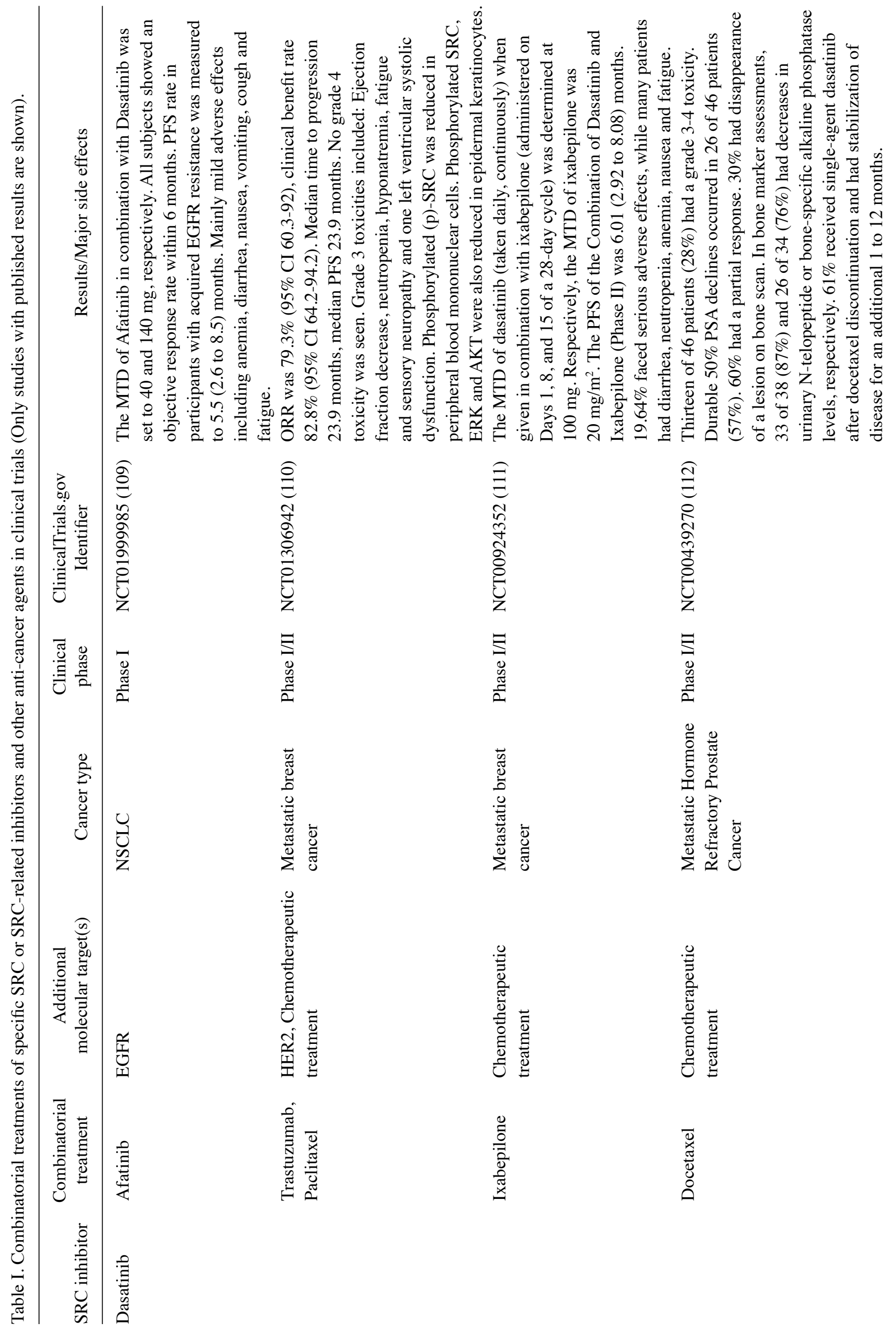




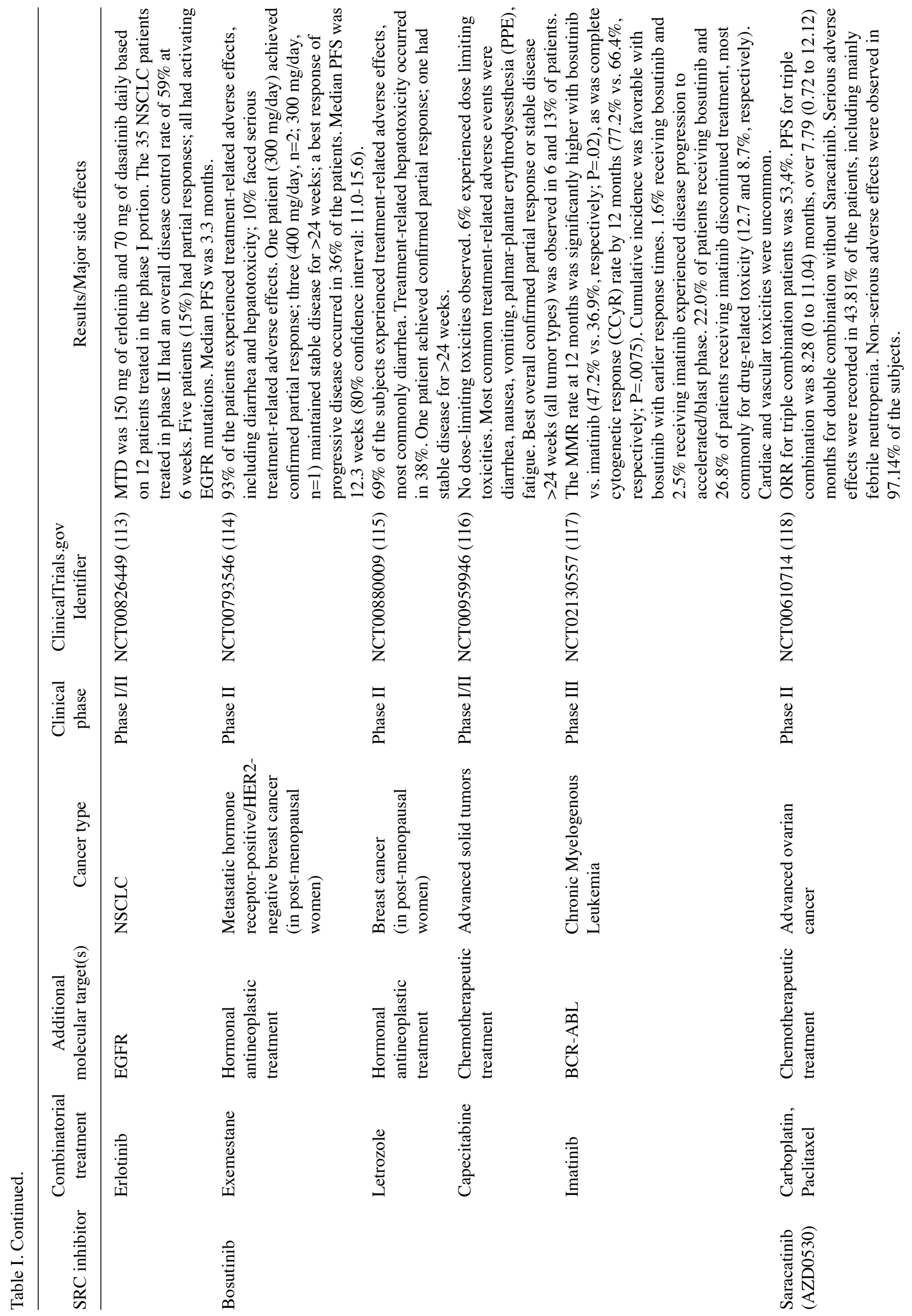


inhibitor approved for the treatment of Philadelphia-positive chronic myeloid leukemia $\left(\mathrm{Ph}^{+} \mathrm{CML}\right)$ and acute lymphoblastic leukemia (ALL), is currently evaluated in clinical trials for the treatment of breast cancer, glioblastoma and other solid tumors (97-99). Dasatinib, an inhibitor of BCR-Abl, SRC, Lck, Fyn, Yes, PDGFR, and other kinases, approved for the treatment of CML is currently evaluated in clinical trials against various solid tumors (100). This inhibitor is also evaluated in combination with insulin-like growth factor 1 Receptor (IGF-1R) antibody AMG479 against embryonal or alveolar rhabdomyosarcoma. Ponatinib, an inhibitor of BCR-Abl, PDGFR, VEGFR, members of the SRC family and other kinases, approved for the treatment of CML and ALL is currently evaluated in clinical trials against several leukemias (101). Vandetanib is an inhibitor of EGFR, VEGFR, RET, members of the SRC family and other kinases, approved for the treatment of medullary thyroid carcinoma and is currently evaluated in clinical trials against numerous solid tumors (102-104). Saracatinib (AZD0530) an SRC and BCR-Abl inhibitor is currently evaluated in clinical trials against colorectal, gastric, ovarian, small and non-small cell lung cancers and against metastatic osteosarcoma in the lung (105-107). A related drug (AZD0424) alone or in combination with other agents is in Phase I clinical trials against various types of solid tumors. KX2-391 is another orally administered small molecule SRC kinase inhibitor with potential antineoplastic activity. Interestingly, instead of binding to the ATP-binding site, like other SRC inhibitors, KX2-391 specifically binds to the peptide substrate binding site of SRC kinase; in this way, kinase activity is eliminated, potentially resulting in the inhibition of primary tumor growth and the suppression of metastasis. This inhibitor is being evaluated in clinical trials against multiple cancer types, either alone or in combination with paclitaxel (108).

At present, there is a critical number of clinical trials that investigate the therapeutic value of putative specific SRC or SRC-related inhibitors as anti-cancer agents, alone or in combination with other agents (Table I) (108). The clinical efficacy of these agents against the above-mentioned cancer types remains to be established.

\section{Conclusion}

The discovery of the Src gene was the trigger for the emergence of other oncogenes, as well as the understanding of the genetic basis of cancer. Therefore, different molecular mechanisms are involved in tumor progression, differentiation and migration. Despite the fact that the $s r c$ gene is now well studied, the molecular pathways mediating cancer progression have not yet been clarified. The contribution of miRNAs and exosomes in the acquisition of malignant phenotype may contribute an emerging therapeutic strategy of combinational therapies with dual pathway inhibition, although further studies are needed. Finally, both exosomes and miRNAs could be useful diagnostic, prognostic and predictive biomarkers in SRC-induced carcinogenesis, thus contributing to a more rational and effective classification and treatment of these patients.

\section{Acknowledgements}

Not applicable. 


\section{Funding}

No funding was received.

\section{Availability of data and materials}

Not applicable.

\section{Authors' contributions}

AS, GS, MG, DAS, SB and VZ contributed to the conception, reference selection and writing of this work, and read and approvel the final manuscript.

\section{Ethics approval and consent to participate}

Not applicable.

\section{Patient consent for publication}

Not applicable.

\section{Competing interests}

DAS is the Editor-in-Chief for the journal, but had no personal involvement in the reviewing process, or any influence in terms of adjudicating on the final decision, for this article. The other authors declare that they have no competing interests.

\section{References}

1. Frame MC: Src in cancer: Deregulation and consequences for cell behaviour. Biochim Biophys Acta 1602: 114-130, 2002.

2. Ishizawar R and Parsons SJ: c-Src and cooperating partners in human cancer. Cancer Cell 6: 209-214, 2004.

3. Summy JM and Gallick GE: Src family kinases in tumor progression and metastasis. Cancer Metastasis Rev 22: 337-358, 2003.

4. Irby RB and Yeatman TJ: Role of Src expression and activation in human cancer. Oncogene 19: 5636-5642, 2000.

5. Yeatman TJ: A renaissance for SRC. Nat Rev Cancer 4: 470-480, 2004.

6. Kim LC, Song L and Haura EB: Src kinases as therapeutic targets for cancer. Nat Rev Clin Oncol 6: 587-595, 2009.

7. Krishnan H, Miller WT and Goldberg GS: SRC points the way to biomarkers and chemotherapeutic targets. Genes Cancer 3 : 426-435, 2012.

8. Brown MT and Cooper JA: Regulation, substrates and functions of src. Biochim Biophys Acta 1287: 121-149, 1996.

9. Playford MP and Schaller MD: The interplay between Src and integrins in normal and tumor biology. Oncogene 23: 7928-7946, 2004

10. Hakak Y and Martin GS: Ubiquitin-dependent degradation of active Src. Curr Biol 9: 1039-1042, 1999.

11. Laszlo GS and Cooper JA: Restriction of Src activity by Cullin-5. Curr Biol 19: 157-162, 2009.

12. Okada M, Nada S, Yamanashi Y, Yamamoto T and Nakagawa $\mathrm{H}$ CSK: A protein-tyrosine kinase involved in regulation of src family kinases. J Biol Chem 266: 24249-24252, 1991

13. Ingley E: Src family kinases: Regulation of their activities, levels and identification of new pathways. Biochim Biophys Acta 1784 56-65, 2008.

14. Rous P: Transmission of a malignant new growth by means of a cell-free filtrate. J Amer Med Assoc 56: 198-198, 1911.

15. Rous P: A sarcoma of the fowl transmissible by an agent from the tumor cells. J Exp Med 13: 397-411, 1911.

16. Bittner JJ: The Milk-influence of breast tumors in mice. Science 95: 462-463, 1942.

17. Gross L: 'Spontaneous' leukemia developing in $\mathrm{C} 3 \mathrm{H}$ mice following inoculation in infancy, with AK-leukemic extracts, or AK-embrvos. Proc Soc Exp Biol Med 76: 27-32, 1951.
18. Shope RE and Hurst EW: Infectious papillomatosis of rabbits: With a note on the histopathology. J Exp Med 58: 607-624, 1933.

19. Sweet $B H$ and Hilleman MR: The vacuolating virus, S.V.40. Proc Soc Exp Biol Med 105: 420-427, 1960.

20. Epstein MA, Achong BG and Barr YM: Virus particles in cultured lymphoblasts from Burkitt's lymphoma. Lancet 1: 702-703, 1964

21. Kurth R and Bannert N: Beneficial and detrimental effects of human endogenous retroviruses. Int J Cancer 126: 306-314, 2010.

22. Boveri T: Zur Frage der Entstehung maligner tumoren. Gustav Fischer, Jena, 1914 (In German).

23. Conney AH, Miller EC and Miller JA: The metabolism of methylated aminoazo dyes. V. Evidence for induction of enzyme synthesis in the rat by 3-methylcholanthrene. Cancer Res 16: 450-459, 1956

24. Cook JW, Hewett CL and Hieger I: 106. The isolation of a cancer-producing hydrocarbon from coal tar. Parts I, II, and III. J Chemical Soc (Resumed): 395-405, 1933.

25. Miller EC and Miller JA: The presence and significance of bound aminoazo dyes in the livers of rats fed para-dimethylaminoazobenzene. Cancer Res 7: 468-480, 1947.

26. Pott P: Chirurgical observations relative to the cataract, the polypus of the nose, the cancer of the scrotum, the different kinds of ruptures, and the mortification of the toes and feet. Carnegy TJ for Hawes L, Clarke W and Collins R, London, 1775.

27. Yamagiwa $\mathrm{K}$ and Ichikawa $\mathrm{K}$ : Experimental study of the pathogenesis of carcinoma. CA Cancer J Clin 27: 174-181, 1977.

28. Temin HM and Rubin H: Characteristics of an assay for rous sarcoma virus and rous sarcoma cells in tissue culture. Virology 6: 669-688, 1958.

29. Duesberg PH and Vogt PK: Differences between ribonucleic acids of transforming and nontransforming avian tumor viruses. Proc Natl Acad Sci USA 67: 1673-1680, 1970.

30. Martin GS: Rous sarcoma virus: A function required for maintenance of transformed state. Nature 227: 1021-1023, 1970.

31. Toyoshima K and Vogt PK: Temperature sensitive mutants of an avian sarcoma virus. Virology 39: 930-931, 1969.

32. Crawford LV and Crawford EM: Properties of rous sarcoma virus purified by density gradient centrifugation. Virology 13 : 227-232, 1961.

33. Baltimore D: Viral Rna-Dependent DNA Polymerase-RnaDependent DNA polymerase in virions of rna tumour viruses. Nature 226: 1209-1211, 1970

34. Temin HM and Mizutani S: RNA-dependent DNA polymerase in virions of Rous sarcoma virus. Nature 226: 1211-1213, 1970

35. Ali M and Baluda MA: Synthesis of avian oncornavirus DNA in infected chicken cells. J Virol 13: 1005-1013, 1974.

36. Baluda MA: Widespread presence, in chickens, of DNA complementary to the RNA genome of avian leukosis viruses. Proc Natl Acad Sci USA 69: 576-580, 1972.

37. Hayward WS and Hanafusa H: Detection of avian tumor virus RNA in uninfected chicken embryo cells. J Virol 11: 157-167, 1973.

38. Stehelin D, Varmus HE, Bishop JM and Vogt PK: DNA related to the transforming gene(s) of avian sarcoma viruses is present in normal avian DNA. Nature 260: 170-173, 1976.

39. Baluda MA and Drohan WN: Distribution of deoxyribonucleic acid complementary to the ribonucleic acid of avian myeloblastosis virus in tissues of normal and tumor-bearing chickens. J Virol 10: 1002-1009, 1972.

40. Hanafusa T, Hanafusa H and Miyamoto T: Recovery of a new virus from apparently normal chick cells by infection with avian tumor viruses. Proc Natl Acad Sci USA 67: 1797-1803, 1970.

41. Perucho M, Goldfarb M, Shimizu K, Lama C, Fogh J and Wigler M: Human-tumor-derived cell lines contain common and different transforming genes. Cell 27: 467-476, 1981.

42. Shih C, Padhy LC, Murray M and Weinberg RA: Transforming genes of carcinomas and neuroblastomas introduced into mouse fibroblasts. Nature 290: 261-264, 1981.

43. Shih C, Shilo BZ, Goldfarb MP, Dannenberg A and Weinberg RA: Passage of phenotypes of chemically transformed cells via transfection of DNA and chromatin. Proc Natl Acad Sci USA 76: 5714-5718, 1979.

44. Reddy EP, Reynolds RK, Santos E and Barbacid M: A point mutation is responsible for the acquisition of transforming properties by the T24 human bladder carcinoma oncogene. Nature 300 $149-152,1982$.

45. Tabin CJ, Bradley SM, Bargmann CI, Weinberg, RA, Papageorge AG, Scolnick EM, Dhar R, Lowy DR and Chang EH: Mechanism of activation of a human oncogene. Nature 300: $143-149,1982$. 
46. Raju TN: The Nobel Chronicles. 1989: John Michael Bishop (b 1936) and Harold Eliot Varmus (b 1939). Lancet 355: 1106 , 2000.

47. Temin HM: Origin of retroviruses from cellular moveable genetic elements. Cell 21: 599-600, 1980

48. Jove $\mathrm{R}$ and Hanafusa $\mathrm{H}$ : Cell transformation by the viral src oncogene. Annu Rev Cell Biol 3: 31-56, 1987.

49. Frame MC: Newest findings on the oldest oncogene; how activated src does it. J Cell Sci 117: 989-998, 2004.

50. Oneyama C and Okada M: MicroRNAs as the fine-tuners of Src oncogenic signalling. J Biochem 157: 431-438, 2015.

51. Ha M and Kim VN: Regulation of microRNA biogenesis. Nat Rev Mol Cell Biol 15: 509-524, 2014.

52. Zhang B, Pan X, Cobb GP and Anderson TA: microRNAs as oncogenes and tumor suppressors. Dev Biol 302: 1-12, 2007.

53. Calin GA and Croce CM: MicroRNA signatures in human cancers. Nat Rev Cancer 6: 857-866, 2006.

54. Mamane Y, Petroulakis E, LeBacquer O and Sonenberg N: mTOR, translation initiation and cancer. Oncogene 25 : 6416-6422, 2006.

55. Wullschleger S, Loewith R and Hall MN: TOR signaling in growth and metabolism. Cell 124: 471-484, 2006.

56. Engelman JA: Targeting PI3K signalling in cancer: Opportunities, challenges and limitations. Nat Rev Cancer 9: 550-562, 2009.

57. Oneyama C, Ikeda J, Okuzaki D, Suzuki K, Kanou T, Shintani Y, Morii E, Okumura M, Aozasa K and Okada M: MicroRNA-mediated downregulation of mTOR/FGFR3 controls tumor growth induced by Src-related oncogenic pathways. Oncogene 30: 3489-3501, 2011.

58. Doghman M, El Wakil A, Cardinaud B, Thomas E, Wang J, Zhao W, Peralta-Del Valle MH, Figueiredo BC, Zambetti GP and Lalli E: Regulation of insulin-like growth factor - mammalian target of rapamycin signaling by microRNA in childhood adrenocortical tumors. Cancer Res 70: 4666-4675, 2010

59. Fornari F, Milazzo M, Chieco P, Negrini M, Calin GA, Grazi GL, Pollutri D, Croce CM, Bolondi L and Gramantieri L: miR-199a-3p regulates mTOR and c-Met to influence the doxorubicin sensitivity of human hepatocarcinoma cells. Cancer Res 70: 5184-5193, 2010

60. Hannigan G, Troussard AA and Dedhar S: Integrin-linked kinase: A cancer therapeutic target unique among its ILK. Nat Rev Cancer 5: 51-63, 2005.

61. Hannigan GE, Leung-Hagesteijn C, Fitz-Gibbon L, Coppolino MG, Radeva G, Filmus J, Bell JC and Dedhar S: Regulation of cell adhesion and anchorage-dependent growth by a new beta 1-integrin-linked protein kinase. Nature 379: 91-96, 1996.

62. McDonald PC, Fielding AB and Dedhar S: Integrin-linked kinase - essential roles in physiology and cancer biology. J Cell Sci 121: 3121-3132, 2008.

63. Oneyama C, Morii E, Okuzaki D, Takahashi Y, Ikeda J, Wakabayashi N, Akamatsu H, Tsujimoto M, Nishida T, Aozasa K and Okada M: MicroRNA-mediated upregulation of integrin-linked kinase promotes Src-induced tumor progression. Oncogene 31: 1623-1635, 2012.

64. Donadelli M, Dando I, Fiorini C and Palmieri M: Regulation of miR-23b expression and its dual role on ROS production and tumour development. Cancer Lett 349: 107-113, 2014.

65. Azuma K, Tanaka M, Uekita T, Inoue S, Yokota J, Ouchi Y and Sakai R: Tyrosine phosphorylation of paxillin affects the metastatic potential of human osteosarcoma. Oncogene 24 4754-4764, 2005.

66. Navon R, Wang H, Steinfeld I, Tsalenko A, Ben-Dor A and Yakhini Z: Novel rank-based statistical methods reveal microRNAs with differential expression in multiple cancer types. PLoS One 4: e8003, 2009.

67. Shi J, Wang S, Zhao E, Shi L, Xu X and Fang M: Paxillin expression levels are correlated with clinical stage and metastasis in salivary adenoid cystic carcinoma. J Oral Pathol Med 39: $548-551,2010$

68. Taylor BS, Schultz N, Hieronymus H, Gopalan A, Xiao Y, Carver BS, Arora VK, Kaushik P, Cerami E, Reva B, et al: Integrative genomic profiling of human prostate cancer. Cancer Cell 18: 11-22, 2010.

69. Majid S, Dar AA, Saini S, Arora S, Shahryari V, Zaman MS, Chang I, Yamamura S, Tanaka Y, Deng G, et al: miR-23b represses proto-oncogene Src kinase and functions as methylation-silenced tumor suppressor with diagnostic and prognostic significance in prostate cancer. Cancer Res 72: 6435-6446, 2012.
70. Kokuda R, Watanabe R, Okuzaki D, Akamatsu H and Oneyama C: MicroRNA-137-mediated Src oncogenic signaling promotes cancer progression. Genes Cells: Jul 2, 2018 (Epub ahead of print).

71. Okuzaki D, Yamauchi T, Mitani F, Miyata M, Ninomiya Y, Watanabe R, Akamatsu H and Oneyama C: c-Src promotes tumor progression through downregulation of microRNA-129-1-3p. Cancer Sci 111: 418-428, 2020.

72. Kennedy S, Clynes M, Doolan P, Mehta JP, Rani S, Crown J and O'Driscoll L: SNIP/p140Cap mRNA expression is an unfavourable prognostic factor in breast cancer and is not expressed in normal breast tissue. Br J Cancer 98: 1641-1645, 2008.

73. Yu Z, Ye S, Hu G, Lv M, Tu Z, Zhou K and Li Q: The RAF-MEK-ERK pathway: Targeting ERK to overcome obstacles to effective cancer therapy. Future Med Chem 7: 269-289, 2015.

74. Zhou P, Xiong T, Yao L and Yuan J: MicroRNA-665 promotes the proliferation of ovarian cancer cells by targeting SRCIN1. Exp Ther Med 19: 1112-1120, 2020.

75. Cao M, Hou D, Liang H, Gong F, Wang Y, Yan X, Jiang X, Wang C, Zhang J, Zen K, et al: miR-150 promotes the proliferation and migration of lung cancer cells by targeting SRC kinase signalling inhibitor 1. Eur J Cancer 50: 1013-1024, 2014

76. Zhao X, Xu Y, Sun X, Ma Y, Zhang Y, Wang Y, Guan H, Jia Z, Li Y and Wang Y: miR-17-5p promotes proliferation and epithelial-mesenchymal transition in human osteosarcoma cells by targeting SRC kinase signaling inhibitor 1. J Cell Biochem 120: 5495-5504, 2019.

77. Yang F, Luo LJ, Zhang L, Wang DD, Yang SJ, Ding L, Li J, Chen D, Ma R, Wu JZ and Tang JH: miR-346 promotes the biological function of breast cancer cells by targeting SRCIN1 and reduces chemosensitivity to docetaxel. Gene 600: 21-28, 2017.

78. Xu X, Wang W, Su N, Zhu X, Yao J, Gao W, Hu Z and Sun Y: miR-374a promotes cell proliferation, migration and invasion by targeting SRCIN1 in gastric cancer. FEBS Lett 589: 407-413, 2015.

79. Ma L, Shao Z and Zhao Y: MicroRNA-374a promotes pancreatic cancer cell proliferation and epithelial to mesenchymal transition by targeting SRCIN1. Pathol Res Pract 215: 152382, 2019.

80. Yuan XL, Wen FQ, Chen XW, Jiang XP and Liu SX: miR-373 promotes neuroblastoma cell proliferation, migration, and invasion by targeting SRCIN1. Onco Targets Ther 12: 4927-4936, 2019.

81. Esquela-Kerscher A and Slack FJ: Oncomirs - microRNAs with a role in cancer. Nat Rev Cancer 6: 259-269, 2006.

82. Lin PY, Yu SL and Yang PC: MicroRNA in lung cancer. Br J Cancer 103: 1144-1148, 2010.

83. Pal MK, Jaiswar SP, Dwivedi VN, Tripathi AK, Dwivedi A and Sankhwar P: MicroRNA: A new and promising potential biomarker for diagnosis and prognosis of ovarian cancer. Cancer Biol Med 12: 328-341, 2015

84. Nada S, Okada M, MacAuley A, Cooper JA and Nakagawa H: Cloning of a complementary DNA for a protein-tyrosine kinase that specifically phosphorylates a negative regulatory site of p60c-src. Nature 351: 69-72, 1991.

85. Nada S, Yagi T, Takeda H, Tokunaga T, Nakagawa H, Ikawa Y, Okada M and Aizawa S: Constitutive activation of Src family kinases in mouse embryos that lack Csk. Cell 73: 1125-1135, 1993.

86. Mitra SK and Schlaepfer DD: Integrin-regulated FAK-Src signaling in normal and cancer cells. Curr Opin Cell Biol 18: 516-523, 2006

87. Fincham VJ, Unlu M, Brunton VG, Pitts JD, Wyke JA and Frame MC: Translocation of Src kinase to the cell periphery is mediated by the actin cytoskeleton under the control of the Rho family of small G proteins. J Cell Biol 135: 1551-1564, 1996.

88. Harris KF, Shoji I, Cooper EM, Kumar S, Oda H and Howley PM: Ubiquitin-mediated degradation of active Src tyrosine kinase. Proc Natl Acad Sci USA 96: 13738-13743, 1999.

89. Reinecke J and Caplan S: Endocytosis and the Src family of non-receptor tyrosine kinases. Biomol Concepts 5: 143-155, 2014.

90. Tu C, Ortega-Cava CF, Winograd P, Stanton MJ, Reddi AL, Dodge I, Arya R, Dimri M, Clubb RJ, Naramura M, et al: Endosomal-sorting complexes required for transport (ESCRT) pathway-dependent endosomal traffic regulates the localization of active Src at focal adhesions. Proc Natl Acad Sci USA 107: 16107-16112, 2010.

91. Tanaka K, Ito Y,Kajiwara K, Nada S and Okada M: Ubiquitination of Src promotes its secretion via small extracellular vesicles. Biochem Biophys Res Commun: Feb 18, 2020 (Epub ahead of print). 
92. Ji H, Greening DW, Barnes TW, Lim JW, Tauro BJ, Rai A, Xu R, Adda C, Mathivanan S, Zhao W, et al: Proteome profiling of exosomes derived from human primary and metastatic colorectal cancer cells reveal differential expression of key metastatic factors and signal transduction components. Proteomics 13: 1672-1686, 2013.

93. DeRita RM, Zerlanko B, Singh A, Lu H, Iozzo RV, Benovic JL and Languino LR: c-Src, insulin-like growth factor I receptor, G-protein-coupled receptor kinases and focal adhesion kinase are enriched into prostate cancer cell exosomes. J Cell Biochem 118: 66-73, 2017.

94.Imjeti NS, Menck K, Egea-Jimenez AL, Lecointre C, Lembo F, Bouguenina H, Badache A, Ghossoub R, David G, Roche S, et al: Syntenin mediates SRC function in exosomal cell-to-cell communication. Proc Natl Acad Sci USA 114 12495-12500, 2017

95. Hikita T, Kuwahara A, Watanabe R, Miyata M and Oneyama C: Src in endosomal membranes promotes exosome secretion and tumor progression. Sci Rep 9: 3265, 2019.

96. Roskoski R Jr: Src protein-tyrosine kinase structure, mechanism, and small molecule inhibitors. Pharmacol Res 94: 9-25, 2015.

97. Daud AI, Krishnamurthi SS, Saleh MN, Gitlitz BJ, Borad MJ, Gold PJ, Chiorean EG, Springett GM, Abbas R, Agarwal S, et al Phase I study of bosutinib, a src/abl tyrosine kinase inhibitor, administered to patients with advanced solid tumors. Clin Cancer Res 18: 1092-1100, 2012.

98. Moy B, Neven P, Lebrun F, Bellet M, Xu B, Sarosiek T, Chow L, Goss P, Zacharchuk C, Leip E, et al: Bosutinib in combination with the aromatase inhibitor letrozole: A phase II trial in postmenopausal women evaluating first-line endocrine therapy in locally advanced or metastatic hormone receptor-positive/HER2-negative breast cancer. Oncologist 19 348-349, 2014.

99. Taylor JW, Dietrich J, Gerstner ER, Norden AD, Rinne ML, Cahill DP, Stemmer-Rachamimov A, Wen PY, Betensky RA, Giorgio DH, et al: Phase 2 study of bosutinib, a Src inhibitor, in adults with recurrent glioblastoma. J Neurooncol 121: 557-563, 2015

100. Araujo J and Logothetis C: Dasatinib: A potent SRC inhibitor in clinical development for the treatment of solid tumors. Cancer Treat Rev 36: 492-500, 2010.

101. Cortes JE, Kim DW, Pinilla-Ibarz J, Le Coutre P, Paquette R, Chuah C, Nicolini FE, Apperley JF, Khoury HJ, Talpaz M, et al A phase 2 trial of ponatinib in Philadelphia chromosome-positive leukemias. N Engl J Med 369: 1783-1796, 2013.

102. Ahn JS, Lee KH, Sun JM, Park K, Kang ES, Cho EK, Lee DH Kim SW, Lee GW, Kang JH, et al: A randomized, phase II study of vandetanib maintenance for advanced or metastatic non-small-cell lung cancer following first-line platinum-doublet chemotherapy. Lung Cancer 82: 455-460, 2013.

103. Gridelli C, Novello S, Zilembo N, Luciani A, Favaretto AG, De Marinis F, Genestreti G, Crino L, Grossi F, Caffo O, et al: Phase II randomized study of vandetanib plus gemcitabine or gemcitabine plus placebo as first-line treatment of advanced non-small-cell lung cancer in elderly patients. J Thorac Oncol 9: 733-737, 2014

104. Sim MW and Cohen MS: The discovery and development of vandetanib for the treatment of thyroid cancer. Expert Opin Drug Discov 9: 105-114, 2014

105. Gucalp A, Sparano JA, Caravelli J, Santamauro J, Patil S, Abbruzzi A, Pellegrino C, Bromberg J, Dang C, Theodoulou M, et al: Phase II trial of saracatinib (AZD0530), an oral SRC-inhibitor for the treatment of patients with hormone receptor-negative metastatic breast cancer. Clin Breast Cancer 11: 306-311, 2011.

106. Laurie SA, Goss GD, Shepherd FA, Reaume MN, Nicholas G, Philip L, Wang L, Schwock J, Hirsh V, Oza A, et al: A phase II trial of saracatinib, an inhibitor of src kinases, in previously-treated advanced non-small-cell lung cancer: The Princess Margaret Hospital phase II consortium. Clin Lung Cancer 15: 52-57, 2014.
107. Molina JR, Foster NR, Reungwetwattana T, Nelson GD, Grainger AV, Steen PD, Stella PJ, Marks R, Wright J and Adjei AA: A phase II trial of the Src-kinase inhibitor saracatinib after four cycles of chemotherapy for patients with extensive stage small cell lung cancer: NCCTG trial N-0621. Lung Cancer 85: 245-250, 2014.

108. U.S. National Library of Medicine: ClinicalTrials.gov. https:// clinicaltrials.gov. Accessed July 1, 2020.

109. U.S. National Library of Medicine: Phase I Trial of Afatinib (BIBW 2992) and dasatinib in non-small cell lung cancer (NSCLC). ClinicalTrials.gov Identifier: NCT01999985. https://ClinicalTrials.gov/show/NCT01999985]. Accessed June 14, 2019.

110. U.S. National Library of Medicine: Dasatinib in combination with trastuzumab and paclitaxel in first line treatment of Her2-Positive MBC patients. ClinicalTrials gov Identifier: NCT01306942. https://ClinicalTrials.gov/show/NCT01306942]. Accessed September 9, 2019.

111. U.S. National Library of Medicine: Trial of dasatinib plus ixabepilone in 2nd or 3rd line metastatic breast cancer. ClinicalTrials. gov Identifier: NCT00924352. https://ClinicalTrials. gov/show/NCT00924352]. Accessed September 29, 2014.

112. U.S. National Library of Medicine: Study of dasatinib and docetaxel in metastatic hormone refractory prostate cancer. ClinicalTrials.gov Identifier: NCT00439270. https://ClinicalTrials.gov/show/NCT00439270]. Accessed November 27, 2013.

113. U.S. National Library of Medicine: Dasatinib and Erlotinib in Non-Small Cell Lung Cancer (NSCLC). ClinicalTrials. gov Identifier: NCT00826449. https://ClinicalTrials. gov/show/NCT00826449]. Accessed October 21, 2015.

114. U.S. National Library of Medicine: Study evaluating bosutinib-exemestane combination vs exemestane alone in post menopausal women with breast cancer. ClinicalTrials. gov Identifier: NCT00793546. https://ClinicalTrials. gov/show/NCT00793546]. Accessed November 5, 2012.

115. U.S. National Library of Medicine: Study evaluating bosutinib-letrozole combination versus letrozole alone in post menopausal women with breast cancer. ClinicalTrials. gov Identifier: NCT00880009. https://ClinicalTrials. gov/show/NCT00880009]. Accessed November 5, 2012.

116. U.S. National Library of Medicine: Study of bosutinib with capecitabine in solid tumors and locally advanced or metastatic breast cancer. ClinicalTrials.gov Identifier: NCT00959946. https://ClinicalTrials.gov/show/NCT00959946]. Accessed February 22, 2013.

117. U.S. National Library of Medicine: A Multicenter Phase 3 , Open-label study of bosutinib versus imatinib in adult patients with newly diagnosed chronic phase chronic myelogenous leukemia. ClinicalTrials.gov Identifier: NCT02130557. https://ClinicalTrials.gov/show/NCT02130557]. Accessed November 14, 2018.

118. U.S. National Library of Medicine: AZD0530 Phase II study in patients with advanced ovarian cancer. ClinicalTrials. gov Identifier: NCT00610714. https://ClinicalTrials. gov/show/NCT00610714]. Accessed September 20, 2011.

119. U.S. National Library of Medicine: Saracatinib and paclitaxel in platinum-resistant ovarian cancer. ClinicalTrials.gov Identifier: NCT01196741. https://ClinicalTrials.gov/show/NCT01196741]. Accessed May 5, 2015.

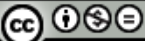

This work is licensed under a Creative Commons Attribution-NonCommercial-NoDerivatives 4.0 International (CC BY-NC-ND 4.0) License. 